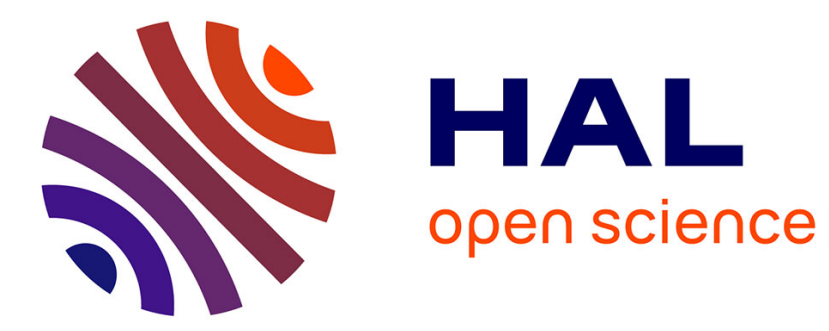

\title{
Occupational exposures and risk of pancreatic cancer
} Miguel Santibañez, Jesús Vioque, Juan Alguacil, Manuela García Hera, Eduardo Moreno-Osset, Alfredo Carrato, Miquel Porta, Timo Kauppinen

\section{To cite this version:}

Miguel Santibañez, Jesús Vioque, Juan Alguacil, Manuela García Hera, Eduardo Moreno-Osset, et al. Occupational exposures and risk of pancreatic cancer. European Journal of Epidemiology, 2010, 25 (10), pp.721-730. 10.1007/s10654-010-9490-0 . hal-00608998

\section{HAL Id: hal-00608998 https://hal.science/hal-00608998}

Submitted on 17 Jul 2011

HAL is a multi-disciplinary open access archive for the deposit and dissemination of scientific research documents, whether they are published or not. The documents may come from teaching and research institutions in France or abroad, or from public or private research centers.
L'archive ouverte pluridisciplinaire HAL, est destinée au dépôt et à la diffusion de documents scientifiques de niveau recherche, publiés ou non, émanant des établissements d'enseignement et de recherche français ou étrangers, des laboratoires publics ou privés. 
EJEP2994 - Revised 2 - 1 July 2010

\title{
Occupational exposures and risk of pancreatic cancer
}

\author{
Miguel Santibañez $^{1,2} \cdot$ Jesús Vioque $^{2,3} \cdot$ Juan Alguacil $^{3,4} \bullet$ Manuela García de la Hera $^{2,3} \bullet$ \\ Eduardo Moreno-Osset $^{5} \cdot$ Alfredo Carrato $^{6} \cdot$ Miquel Porta $^{3,7} \cdot$ Timo Kauppinen $^{8}$ \\ for the PANESOES Study Group*
}

1. Research Support Unit, IFIMAV-Marques de Valdecilla Foundation, Santander, Spain

2. Departamento de Salud Pública, Universidad Miguel Hernández, Elche-Alicante, Spain.

3. CIBER de Epidemiología y Salud Pública (CIBERESP), Spain.

4. Department of Environmental Biology and Public Health, Huelva University, Spain.

5. Servicio de Medicina Digestiva, Hospital Universitario Dr. Peset, Universidad de Valencia, Valencia, Spain.

6. Servicio de Oncología Médica, Hospital General de Elche, Elche, Spain.

7. Institut Municipal d'Investigació Mèdica (IMIM-Hospital del Mar) and Universitat Autònoma de Barcelona, Catalonia, Spain.

8. Finnish Institute of Occupational Health (FIOH), Helsinki, Finland

Corresponding author: Juan Alguacil, MD, PhD.

Departamento de Biología Ambiental y Salud Pública, Universidad de Huelva, Avda. Fuerzas Armadas s/n, E-21071 Huelva, Spain

Tel. +34959219890

Fax +34 959219876

E-mail: alguacil@dbasp.uhu.es 


\section{Abbreviations:}

Chlorinated Hydrocarbon Solvents (CHC)

Confidence Intervals $(\mathrm{Cl})$

Exocrine Pancreatic Cancer (EPC)

Finnish job-exposure matrix (FINJEM)

Odds ratio (OR)

Odds ratio for the highest level of exposure (ORh)

Odds ratio restricted to men (OR men)

Odds ratio restricted to women (OR women)

Polycyclic Aromatic Hydrocarbons (PAH)

Spanish National Classification of Occupations - 1994 (CNO94)

Standard Deviation (SD)

Running title: Occupational exposures and pancreatic cancer in Spain

Word count (abstract): 234

Word count (manuscript): 2,971

Number of Tables: 2

Number of references: 58

Key words: chlorinated hydrocarbons; occupation; occupational exposures; pancreatic neoplasms. 
* Members of PANESOES Study Group: Jesus Vioque (principal investigator and coordinator of the study), Esperanza Ponce, María Guillén, Miguel Santibáñez, Xavier Barber, Manuela García de la Hera Departamento de Salud Pública, Universidad Miguel Hernández, Elche-Alicante, Spain; Miguel Bixquert, Jorge Alonso, Vicente Cervera, Remedios Giner, Juan Ruiz, Carlos SanchosAldás, Javier Arenas, Hospital Arnau Vilanova de Valencia; Joaquin Berenguer, Teresa Sala, Sonia Pascual, Liria Argüello, Marco Bustamante, Salvador Sancho, Constantino Herranz, Jorge Aparicio, Dr. Baixauli, Jorge Mir, Pedro Sendrá, Hospital La Fe de Valencia; Enrique Medina, Alicia Tomé, Luis Ferrer, Ramón Truyenque, Luis Olabarrieta, Ricardo Fabra, Carlos Camps, Jose Maria Vicent, Hospital General de Valencia; Eduardo Moreno-Osset, Ramón Añón, José Ballester, Vicente Alfonso, Dr. Martínez-Abad, Francisco Blanes, Carmen Molins, Daniel Almenar, Santiago Olmos, Dr. Fenollosa, Hospital Doctor Peset de Valencia; Adolfo Benages-Martinez, Andrés PeñaAldea, Dra. I. Pascual, Dr. García-Conde, Andrés Cervantes, Pilar Azagra, Dr. Lledó, Blas Flor, Vicente Martí, Hospital Clínico de Valencia; Miguel Pérez-Mateo, Juan Antonio Casellas, Eva Girona, Jose Ramón Aparicio, Mar López, Antonio Arroyo, Fernando Camuñas, Jesus de Anta, Hospital General de Alicante; Juan Custardoy, Concepción Martínez, Enrique Gaspar, Eduardo Muñoz, Hospital Comarcal de la Vega Baja; Alfredo Carrato, Maria Luisa Gozálvez, Rafael Calpena, Dr. Gassent, Dr. Pérez, Carlos Sillero C, Hospital General de Elche; Justo Medrano, Francisco Mauri, Marta Corona, Jorge Minguel, Hospital Universitario Sant Joan de Alicante. 


\section{ABSTRACT}

The objective was to analyze the relationship between occupation (and specific occupational exposures) and risk of exocrine pancreatic cancer (EPC). We conducted a multicenter hospitalbased case-control study in Eastern Spain. We included 161 incident cases of EPC $(59.6 \%$ men, 94 with histological confirmation, of whom $80 \%$ had ductal adenocarcinoma). Cases were frequency-matched with 455 controls by sex, age and province of residence. Information was elicited using structured questionnaires. Occupations were coded according to the Spanish version of the International Standard Classification of Occupations 1988. Occupational exposure to a selection of carcinogenic substances was assessed with the Finnish Job-Exposure Matrix (FINJEM). Odds ratios (OR) and 95\% confidence intervals $(\mathrm{Cl})$ were estimated by multiple logistic regression, adjusting for sex, age, province, education, alcohol and smoking. A higher risk of EPC was associated with having worked as 'Miners, shotfirers, stone cutters and carvers', 'Machinery mechanics and fitters', 'Building trades workers' and 'Motor vehicle drivers' in men, 'Office Clerks' in women, and 'Waiters' in both sexes. Cases with ductal adenocarcinomas were more likely to have been exposed to chlorinated hydrocarbon solvents $(\mathrm{OR}=4.1,95 \% \mathrm{Cl}: 1.1-15.2, \mathrm{p}$-trend $=$ 0.04). We also observed significant associations with exposure to 'synthetic polymer dust exposure' and 'ionizing radiation'. Suggestive increases in risk were observed for 'pesticides', 'diesel and gasoline engine exhaust', and 'hydrocarbon solvents'. Results support the hypothesis that occupational exposure to chlorinated hydrocarbon solvents is associated with exocrine pancreatic cancer. 


\section{INTRODUCTION}

The etiology of exocrine pancreatic cancer (EPC) remains largely unknown. The only firmly established and modifiable risk factor is smoking, but it explains only a fraction of cases [1], and the association seems somewhat weaker in Mediterranean countries [2, 3]. Factors that probably cause moderate increases in risk include age, diabetes, chronic pancreatitis, and obesity [1].

The highest incidence and mortality rates of pancreatic cancer are found in developed countries [4]. Pancreatic cancer is the fourth leading cause of cancer death in the United States [5], and the sixth leading cause of cancer death in Europe [6]. Although mortality rates had been low in Spain, mortality increased in both sexes over the past 40 years [7], most likely due to a combination of an improvement in death certification and changes in lifestyle and environmental factors.

A wide spectrum of occupational exposures has been related to an increased risk of EPC [1,9]. A meta-analysis on occupation and EPC suggested that some occupational exposures -like chlorinated hydrocarbon solvents, other organic solvents, chromium, nickel, silica, and organochlorine insecticides- may increase the risk $[9,10]$. Other specific agents that might increase EPC risk include asbestos and ionising radiations [1]. Among the specific agents assessed in epidemiologic studies, chlorinated hydrocarbon solvents is probably the exposure that has been most consistently associated with EPC [11]. In Spain, the association between occupation and EPC has been addressed by one study, which suggested increased risks for pesticides, aniline derivatives, dyes and organic pigments, and benzo[a]pyrene [12-14].

In this study we evaluated the association between risk of EPC and occupational exposures in Spain. We also explored the association between specific agents and exposures through the Finnish job-exposure matrix (FINJEM). 


\section{MATERIAL AND METHODS}

\section{Subjects}

This research was part of the PANESOES study, a hospital-based case-control study designed to explore the influence of major lifestyles and diet on the risk of three gastrointestinal cancers: pancreas, oesophagus and stomach. Details of this study have been published elsewhere $[15,16]$. The PANESOES Study planned to recruit approximately 200 cases for oesophagus cancer, 200 for pancreatic cancer, 400 cases for stomach cancer, and 450 controls frequency matched to the expected distribution of case subjects of the overall PANEOES study by sex, age and province (Alicante, Valencia). Eligible subjects were Spanish-speaking men and women, 30-80 years old, and hospitalized between January 1995 and March 1999 in any of nine participant hospitals in the provinces of Alicante and Valencia, in the Mediterranean part of Spain. All subjects were informed of the study objectives and gave their informed consent prior to their inclusion in the study. Research protocols were approved by the local ethics and/or research committees of the participating Hospitals and the University.

One-hundred and sixty-one incident cases were finally included (96 men and 65 women) out of the 199 cases initially diagnosed as EPC. Twelve cases (ten men and 2 women) could not be interviewed due to their poor health status or refusal to participate in the study. Twenty five cases were excluded for lack of diagnosis consensus by a panel of clinical experts on pancreatic diseases, and one case did not answer the occupational exposure section of the questionnaire. Diagnosis was obtained by histological confirmation in 95 cases (76 ductal adenocarcinoma and 19 other histologies) and consensus from clinical evidence by an expert group (AC, EMO, JV) in the remaining 67 cases. Cases and controls were recruited concurrently. A wide inclusion criterion was used to select controls from diseases not related a priori to the main exposures of interest (tobacco, alcohol and diet). The overall participation rate of the 457 eligible controls was $99.6 \%$, leaving 455 control subjects with completed interviews for analyses. The distribution of the main diagnostic groups for controls was: hernias (28.3\%), fractures or injuries (35.2\%), appendicitis (6.4\%), eventrations (5.5\%), acute cholecystitis (2.6\%), and other diagnoses (21.9\%).

\section{Exposure assessment}

Face-to-face interviews were conducted in-hospital for all participants by trained interviewers, using a structured questionnaire. Eighty-eight percent of the interviews with cases were conducted with the patient ( $62 \%$ with the patient alone and $26 \%$ with the patient receiving help from a relative) whereas in controls, $70 \%$ were performed alone and $26 \%$ with help. Proxies provided information 
for the other cases and controls. While interviewers could not be blinded to the case/control status, they were unaware of the main study hypothesis and were trained to administer strictly the structured questionnaires in an equal manner to cases and controls alike.

We collected information on demographic characteristics, tobacco and alcohol use, medical history, other lifestyle factors and occupational history. The interview elicited details on usual tobacco use including tobacco type and the age at which the habit started and stopped. A "never smoker" was defined as someone who had smoked fewer than 100 cigarettes or less than one cigarette per day for one year. A "former smoker" was defined as someone having stopped smoking 1 or more years before the interview. Alcohol consumption patterns were assessed through inquiries into the usual intake of alcoholic beverages. A "never drinker" was someone having consumed less than one drink per month. A "former drinker" was defined as having stopped drinking at least one year before the interview.

Information was elicited for the two main occupations for each person: job title, number of years worked and the products and/or substances that were used in each occupation. Where there was any doubt about the two main occupations, information on a third occupation was collected. Main occupations were defined as those occupations in which a subject had worked longest. All reported occupations were coded according to the Spanish National Classification of Occupations of 1994 (CNO94), which is based on the European Union version of the International Standard Classification of Occupations, ISCO 88 (COM). The coding process was carried out by an occupational physician (MS) who was blinded to the case-control status of the study subjects. The proportions of cases and controls reporting one, two or three occupations were very similar $(p=$ 0.57). The median of the total number of worked years was $39.9(S D=15.7)$ in cases and 38.4 $(S D=14.8)$ in controls $(p=0.29)$.

In addition, we used the FINJEM job exposure matrix [17] to explore occupational exposure to 21 chemical agents, four physical exposures, and two ergonomic exposures. Exposure in FINJEM is characterised by two metrics: the prevalence (probability) of exposure (range 0.06-1) and the average level of exposure (intensity) for each analysed agent (mostly in $\mathrm{mg} / \mathrm{m}^{-3}$ or in ppm). We used their product as the exposure metric to classify exposure to each agent in three categories: substantial (high), low, and unexposed. The cut-off points between low and substantial were set as close as possible to the $75^{\text {th }}$ percentile of the distribution of the product of the probability and the intensity of exposure in controls. 


\section{Statistical analyses}

We only estimated the risk of EPC for occupations held for at least one year. In addition, we only estimated the effects of job titles with at least 10 exposed subjects, combining cases and controls ( 5 subjects for a priori high risk occupational groups), ascending from the more general one-digit classification of major occupational groups to the more specific four-digit classification of occupations (subcategories). The reference group comprised subjects who had never been in the occupation of interest [12]. We performed analyses for all types of EPC combined, and for ductal adenocarcinoma. We also repeated the analyses for exposures of at least 15 years.

Adjusted odds ratios (OR) and 95\% confidence intervals $(\mathrm{Cl})$ were calculated using unconditional logistic regression $[18,19]$. All regression models were built to include categorical covariates for the three frequency matched factors: sex (men, women), age ( $<60$ years, 60-70 and $>70$ years), and hospital origin (Valencia/Alicante). We also forced the inclusion of categorical covariates for known risk factors of pancreatic cancer: educational level (<primary, primary completed, and high school or higher), tobacco smoking, and alcohol consumption. Other possible confounding variables were also retained in the models when they materially altered the estimates. Final models were chosen coherently with the nature of the variables and the study objectives. Tests for trend in the ORs across exposure strata were calculated through logistic models that included categorical terms as continuous variables, with each model including all potential confounders. For trend-tests, we used the likelihood ratio test statistic with one degree of freedom. The level of statistical significance was set at 0.05 and all tests were two-tailed. All analyses were performed with SPSS v.13.0. 


\section{RESULTS}

EPC cases were on average 2.5 years older than controls $(p=0.01)$, presented a similar distribution by sex and educational level, and reported a higher prevalence of cigarette smoking $(p=0.009)$ and a slightly higher prevalence of alcohol consumption $(p=0.12)$ than controls.

Table 1 shows risk estimates for a selection of job-titles by gender. Most associations were stronger after restricting the analyses to cases with histologically confirmed adenocarcinoma: 'building finishers and related trades workers (CNO94 code 72)' (OR men $=3.58$; 95\% Cl: 1.0312.44), 'miners, shotfirers, stone cutters and carvers (code 742)' (OR men $=8.14 ; 95 \% \mathrm{Cl}$ : 1.55 42.68), 'machinery and electrical and electronic equipment mechanics and fitters (code 76)' (OR men $=3.61 ; 95 \% \mathrm{Cl}: 1.24-10.47)$ and 'heavy truck and lorry drivers (code 863)' (OR men = 3.46; $95 \% \mathrm{Cl}: 1.01-11.83)$. Although they were not statistically significant, in men suggestive associations were also found for 'employed skilled workers in agricultural activities (code 602)' (OR men= 2.35; 95\% Cl: 0.51-10.92), 'fibre preparers (code 7931)' (OR men $=3.42 ; 95 \% \mathrm{Cl}: 0.62-$ 18.71), 'wood-processing-plant operators (code 8141)' (OR men $=2.38 ; 95 \% \mathrm{Cl}: 0.35-16.17)$, and 'metal and mineral products machine operators (code 831)' (OR men=3.20; 95\% $\mathrm{Cl}: 0.78-13.01$ ). In women, an increase of risk was observed among 'other office clerks (code 43)' (OR women = 14.20; $95 \% \mathrm{Cl}: 1.16-173.67)$. In all of these job-titles, associations were similar or increased slightly when analyses were restricted to occupations held for at least 15 years (data not shown).

Table 2 shows risk estimates for specific occupational exposures evaluated by FINJEM in both sexes. A positive association was apparent for high exposure to chlorinated hydrocarbon solvents: the odds ratio for the highest level of exposure (ORh) was 1.99 (95\% Cl: 0.62-6.42); it became statistically significant when the analysis was restricted to ductal adenocarcinomas $(O R h=4.11$; $\left.95 \% \mathrm{Cl}: 1.11-15.23, \mathrm{p}_{\text {trend }}=0.04\right)$. Other significant associations were apparent among ductal adenocarcinomas, specially in men, for asbestos (ORh men= 7.54; 95\% Cl: $1.61-35.19 ; p_{\text {trend }}=$ 0.001), and for synthetic polymer dust exposure (ORh men $=5.40 ; 95 \% \mathrm{Cl}: 1.04-28.11)$. There was also evidence of an association for ionizing radiation (OR men=16.73; 95\% Cl: 2.32-120), 
high exposure to pesticides $(\mathrm{ORh}$ men $=3.54 ; 95 \% \mathrm{Cl}: 0.83-15.21)$, diesel engine exhaust $(\mathrm{ORh}$ men=1.88; 95\% Cl: 0.72-4.90), and gasoline engine exhaust (ORh men=1.85; 95\% Cl: $0.71-$ 4.80).

Finally, when analyses were restricted to occupational exposures with a duration of 15 years or longer, associations were not statistically significant, but for the agents mentioned above (e.g., chlorinated hydrocarbon solvents) point estimates were similar or slightly higher (data not shown). 


\section{DISCUSSION}

We found a significant increase in EPC risk in men among the occupational job-titles 'machinery mechanics and fitters', 'miners', 'building trades workers' and 'motor vehicle drivers'; and among 'office clerks', in women. With respect to occupational exposure to specific agents or groups of agents, we observed significant associations with dose-response trends for 'chlorinated hydrocarbon solvents', and 'asbestos'; and significant increases in risk for 'synthetic polymer dust exposure' and 'ionizing radiation'. A suggestion of association was apparent for 'pesticides', and for 'diesel and gasoline engine exhaust'. Most associations became stronger when analyses were restricted to histologically confirmed ductal adenocarcinomas.

Occupational exposure to chlorinated hydrocarbon solvents $(\mathrm{CHC})$ seems the most consistent occupational association with EPC observed in epidemiological studies. Our results are consistent with the meta-analysis by Ojajärvi et al., based on 20 populations from Europe, North America, and Asia during 1969-1998, in which a statistically significant meta-relative risk of 1.4 (95\% Cl: 1.0-1.8) was found for $\mathrm{CHC}$ and related compounds [9]. In a more comprehensive and detailed metaanalysis for $\mathrm{CHC}$ published by the same authors one year later, significant excesses of EPC were found for metal degreasing and related jobs and dry cleaning [11]. Among specific $\mathrm{CHC}$ solvents with known or suspected human carcinogenicity [20], evidence of weak associations was found for trichloroethylene, tetrachloroethylene, methylene chloride, vinyl chloride, PCBs, and chlorohydrin manufacture, but not for carbon tetrachloride [11]. Nevertheless, evidence from animal studies for the association between $\mathrm{CHC}$ compounds and EPC is scant. It was not feasible to collect information on specific chlorinated organic solvents from our cases, most of whom had severe EPC at the time of the interview, as usual. However, our results support the hypothesis that the association between $\mathrm{CHC}$ and EPC is real: first, because it was strengthened when the analysis was restricted to histologically confirmed cases; and second, because there was a significant doseresponse trend for long duration exposures of 15 years or more. 
The associations found among miners, shotfirers and stone cutters and carvers in men are based on just a few exposed cases and controls; furthermore, they involve a wide range of activities and exposures, such as ionizing radiation, asbestos, oil mist, carbon monoxide, silica dust and other mineral dust and fibres. Although a Finnish study reported an increased risk among quarry miners [21], and the Ojajärvi meta-analysis found in a significant excess risk for silica dust [9], the evidence of an association among miners is scarce.

The association found for ductal adenocarcinoma in men highly exposed to asbestos according to FINJEM was based on three cases and seven controls. The job titles of these cases were miners $(n=1)$ and shotfirers $(n=2)$. As there was no asbestos exposure in Spanish mines, the association is likely to be due to overassignment of exposure to asbestos from FINJEM to Spanish workers. In a previous study on pancreatic cancer in Spain, industrial hygienists considered only 1 case and 2 controls as exposed to asbestos (none of them miners), while FINJEM identified 15 cases and 23 controls in the highly exposed category [13].

The significant association between ionizing radiation and ductal adenocarcinoma was based on the three cases and two controls. Although a Finnish population based case-control study that assigned occupational exposure to ionizing radiations by job-exposure matrix also found an elevated odds ratio for ionizing radiation $(\mathrm{OR}=4.3(95 \% \mathrm{Cl}: 1.6-11.4)$ [22]), results from studies in other exposed workers are contradictory [23-25]. A collaborative analysis of 11 cohorts of underground miners found an association between cumulative exposure to radon and pancreatic cancer [26]. No clear evidence of a link between EPC and occupational exposure to radiation was identified after a comprehensive review up to 1990 [27]. The associations for 'fibre preparers' and 'synthetic polymer dust' are not supported by previous epidemiological studies.

Although we found a significant association among clerks in women, we did not find an association for sedentary work assessed through FINJEM. Clerical occupations are commonly found to convey a small elevation in risk of EPC [12, 28-30]. Physical activity may play a modest role on EPC [31]. 
Associations in wide occupational groups such as 'machinery mechanics and fitters', 'machine operators' and 'building trades workers' are supported by previous studies [12, 32-39]. Possible responsible agents might be chlorinated solvents, used while cleaning, as well as mineral oils with PAHs and nitrosamines [40]. The increased risk in men in the group of vehicle drivers -and particularly, heavy truck and lorry drivers- is consistent with other studies [21, 35, 41, 42], and with the suggestive increased risk for diesel and gasoline engine exhaust also found in this study.

While a number of case-control studies examining pesticides observed elevated risks similar to our study [13, 43-46], other studies have not [47-50]. Certain types of pesticides seem to be more related to EPC than others. The organochlorine insecticide DDT has been positively linked in some studies [45, 51, 52]; also, the Ojajärvi meta-analysis found a significant elevated risk with organochlorine insecticide exposure [9]. Ongoing studies should help clarify the potential relationship between organochlorine compounds and risk of EPC [53].

Similarly to other hospital based case-control studies exploring occupational exposures, this study has some limitations, such as low numbers of exposed subjects for uncommon occupational exposures or the high number of comparisons. To increase the statistical power in our study -with only 3 cases less than the largest case-control study on occupation published in Spain [12, 13]-, we used about 3 controls per case, resulting in $80 \%$ power to identify two-fold associations at the $5 \%$ significant level for exposures with a $12 \%$ prevalence among controls. Other caveats relate to the lack of a real adaptation of FINJEM to the specific exposure circumstances in Spain, and to the lack of a control for other putative risk factors of EPC, such as diabetes mellitus, obesity or dietary factors. In contrast, we compared the effect for every job title and occupational exposure to the remaining ones; thus, it may be possible that the effect for some exposures was underestimated because of the inclusion in the reference category of other occupations and substances that also showed an increase in risk of EPC.

Strengths of the study include the high percentage of subjects with data on occupational history ( $81 \%$ of cases and $95 \%$ of controls), and the high percentage of interviews performed directly with 
the study subjects (88\%). These figures are seldom achieved in pancreatic cancer, and are a consequence of the rapid identification of cases in our study [52-58].

In summary, results lend support to the hypothesis of an association between occupational exposure to chlorinated hydrocarbon solvents and EPC risk, which is probably the most consistent occupational association with EPC in the literature. A few other occupations and occupational exposures also appeared to increase risk and are likewise in accordance with some previous studies.

Acknowledgments This work was partly supported by Fondo de Investigación Sanitaria (FIS 91/0435), Fundación Bienvenida Navarro Luciano-Trípodi, and Fundación Hospital Universitario de Elche (cod 01/07) Generalitat Valenciana (EVES 030/2005; CTGCA/2002/06; G03/136). We would also like to acknowledge editorial assistance provided by Jonathan Whitehead. 


\section{References}

1 Weiderpass E, Partanen T, Kaaks R, et al. Occurrence, trends and environment etiology of pancreatic cancer. Scand J Work Environ Health 1998;24:165-74.

2 Ferraroni M, Negri E, La Vecchia C, et al. Socioeconomic indicators, tobacco and alcohol in the aetiology of digestive tract neoplasms. Int J Epidemiol 1989;18:556-62.

3 Fernandez E, La Vecchia C, Decarli A. Attributable risks for pancreatic cancer in northern Italy. Cancer Epidemiol Biomarkers Prev 1996;5:23-7.

4 Parkin D, Bray F, Ferlay J, et al. Estimating the world cancer burden: Globocan 2000. Int J Cancer 2001;94:153-6.

5 Cancer facts \& figures 2004. Atlanta: American Cancer Society, Inc. 2004.

6 Bray F, Sankila R, Ferlay J, et al. Estimates of cancer incidence and mortality in Europe in 1995. Eur J Cancer 2002;38:99-166.

7 Sahmoun A, D'Agostino RJ, Bell R, et al. International variation in pancreatic cancer mortality for the period 1955-1998. Eur J Epidemiol 2003;18:801-16.

8 Anderson K, Potter J, Mack T. Cancer of the Pancreas. In: Schottenfeld D FJ, ed. Cancer epidemiology and prevention. New York: Oxford University Press 2007:721-62.

9 Ojajarvi IA, Partanen TJ, Ahlbom A, et al. Occupational exposures and pancreatic cancer: a meta-analysis. Occup Environ Med 2000;57:316-24.

10 Seilkop S. Occupational exposures and pancreatic cancer: a meta-analysis. Occup Environ Med 2001;58:63-4.

11 Ojajärvi A, Partanen T, Ahlbom A, et al. Risk of pancreatic cancer in workers exposed to chlorinated hydrocarbon solvents and related compounds: a meta-analysis. Am J Epidemiol 2001;153:841-50.

12 Alguacil J, Porta M, Benavides FG, et al. Occupation and pancreatic cancer in Spain: a casecontrol study based on job titles. Int J Epidemiol 2000;29:1004-13.

13 Alguacil J, Kauppinen T, Porta M, et al. Risk of pancreatic cancer and occupational exposures in Spain. Ann Occup Hyg 2000;44:391-403.

14 Alguacil J, Porta M, Malats N, et al. Occupational exposure to organic solvents and K-ras mutations in exocrine pancreatic cancer. Carcinogenesis 2002;23:101-6.

15 Santibañez M, Vioque J, Alguacil J, et al. Occupational Exposures and Risk of Oesophageal cancer by Historical Type: A case-control study in Eastern Spain. Occup Environ Med 2008;65:774-81.

16 Vioque J, Barber X, Bolumar F, et al. Esophageal cancer risk by type of alcohol drinking and smoking: a case-control study in Spain. BMC Cancer 2008;8:221.

17 Kauppinen T, Toikkanen J, Pukkala E. From cross-tabulations to multipurpose exposure information systems: a new job-exposure matrix. Am J Ind Med 1998;33:409-17.

18 Armitage P, Berry G. Statistical Methods in Medical Research. 3rd edition. Oxford: Blackwell. 1994.

19 Breslow N, Day N. Statistical methods in cancer research. The analysis of case-control studies. IARC Sci Publ 1980;I:5-338.

20 IARC working group on the evaluation of carcinogenic risks to humans: IARC monographs on the evaluation of carcinogenic risks to humans. Alcohol drinking. Volume 44. Lyon, France: International Agency for Research on Cancer; 1988. 
21 Partanen T, Kauppinen T, Degerth R, et al. Pancreatic cancer in industrial branches and occupations in Finland. Am J Ind Med 1994;25:851-66.

22 Kauppinen T, Partanen T, Degerth R, et al. Pancreatic cancer and occupational exposures. Epidemiology 1995;6:498-502.

23 Smith P, Doll R. Mortality from cancer and all causes among British radiologists. Br J Radiol 1981;54:187-94.

24 Tolley $\mathrm{H}$, Marks S, Buchanan J, et al. A further update of the analysis of mortality of workers in a nuclear facility. Radiat Res 1983;95:211-3.

25 Polednak A, Stehney A, Lucas H. Mortality among male workers at a thorium-processing plant. Health Phys 1983;44 Suppl 1:239-51.

26 Darby S, Whitley E, Howe G, et al. Radon and cancers other than lung cancer in underground miners: a collaborative analysis of 11 studies. J Natl Cancer Inst 1995;87:378-84.

27 Committee on the Biological Effects of lonizing Radiation (BEIR V), National Research Council. Health effects of exposure to low levels of ionizing radiation. Washington DC: National Academy Press. 1990.

28 Weiderpass E, Vainio H, Kauppinen T, et al. Occupational exposures and gastrointestinal cancers among Finnish women. J Occup Environ Med 2003;45:305-15.

29 Kernan G, Ji B, Dosemeci M, et al. Occupational risk factors for pancreatic cancer: a casecontrol study based on death certificates from 24 U.S. states. Am J Ind Med 1999;36:260-70.

30 Falk R, Pickle L, Fontham E, et al. Occupation and pancreatic cancer risk in Louisiana. Am J Ind Med 1990;18:565-76.

31 Bao Y, Michaud D. Physical activity and pancreatic cancer risk: a systematic review. Cancer Epidemiol Biomarkers Prev 2008;17:2671-82.

32 Yassi A, Tate R, Routledge M. Cancer incidence and mortality in workers employed at a transformer manufacturing plant: update to a cohort study. Am J Ind Med 2003;44:58-62.

33 Alguacil J, Porta M, Kauppinen T, et al. Occupational exposure to dyes, metals, polycyclic aromatic hydrocarbons and other agents and K-ras activation in human exocrine pancreatic cancer. Int J Cancer 2003;107:635-41.

34 Ji B, Silverman D, Dosemeci M, et al. Occupation and pancreatic cancer risk in Shanghai, China. Am J Ind Med 1999;35:76-81.

35 Mallin K, Rubin M, Joo E. Occupational cancer mortality in Illinois white and black males, 19791984, for seven cancer sites. Am J Ind Med 1989;15:699-717.

36 Silverstein M, Park R, Marmor M, et al. Mortality among bearing plant workers exposed to metalworking fluids and abrasives. J Occup Med 1988;30:706-14.

37 Mur J, Moulin J, Meyer-Bisch C, et al. Mortality of aluminium reduction plant workers in France. Int J Epidemiol 1987;16:257-64.

38 Rockette $\mathrm{H}$, Arena V. Mortality studies of aluminum reduction plant workers: potroom and carbon department. J Occup Med 1983;25:549-57.

39 Maruchi N, Brian D, Ludwig J, et al. Cancer of the pancreas in Olmsted County, Minnesota, 1935-1974. Mayo Clin Proc 1979;54:245-9.

40 Calvert G, Ward E, Schnorr T, et al. Cancer risks among workers exposed to metalworking fluids: a systematic review. Am J Ind Med 1998;33:282-92.

41 Alguacil J, Pollán M, Gustavsson P. Occupations with increased risk of pancreatic cancer in the Swedish population. Occup Environ Med 2003;60:570-6. 
42 Viadana E, Bross I, Houten L. Cancer experience of men exposed to inhalation of chemicals or to combustion products. J Occup Med 1976;18:787-92.

43 Ji B, Silverman D, Stewart P, et al. Occupational exposure to pesticides and pancreatic cancer. Am J Ind Med 2001;39:92-9.

44 Porta M, Malats N, Jariod M, et al. Serum concentrations of organochlorine compounds and Kras mutations in exocrine pancreatic cancer. Lancet 1999;354:2125-9.

45 Fryzek J, Garabrant D, Harlow S, et al. A case-control study of self-reported exposures to pesticides and pancreas cancer in southeastern Michigan. Int J Cancer 1997;72:62-7.

46 Friedman $\mathrm{G}$, van den Eeden $\mathrm{S}$. Risk factors for pancreatic cancer: an exploratory study. Int $\mathrm{J}$ Epidemiol 1993;22:30-7.

47 Cocco P, Kazerouni N, Zahm S. Cancer mortality and environmental exposure to DDE in the United States. Environ Health Perspect 2000;108:1-4.

48 Wong $\mathrm{O}$, Brocker $\mathrm{W}$, Davis $\mathrm{H}$, et al. Mortality of workers potentially exposed to organic and inorganic brominated chemicals, DBCP, TRIS, PBB, and DDT. Br J Ind Med 1984;41:15-24.

49 Wiklund K, Dich J, Holm L, et al. Risk of cancer in pesticide applicators in Swedish agriculture. $\mathrm{Br} J$ Ind Med 1989;46:809-14.

50 Brown D. Mortality of workers employed at organochlorine pesticide manufacturing plants--an update. Scand J Work Environ Health 1992;18:155-61.

51 Beard J, Sladden T, Morgan G, et al. Health impacts of pesticide exposure in a cohort of outdoor workers. Environ Health Perspect 2003;111:724-30.

52 Garabrant D, Held J, Langholz B, et al. DDT and related compounds and risk of pancreatic cancer. J Natl Cancer Inst 1992;84:764-71.

53 Porta M, López T, Pumarega J, et al. In pancreatic ductal adenocarcinoma blood concentrations of some organochlorine compounds and coffee intake are independently associated with KRAS mutations. Mutagenesis 2009;24:513-21.

54 Malats N, Real F, Porta M. DDT and pancreatic cancer. J Natl Cancer Inst 1993;85:328-9.

55 Porta M, Malats N, Piñol JL, et al. Diagnostic certainty and potential for misclassification in exocrine pancreatic cancer. J Clin Epidemiol 1994;47:1069-79.

56 Porta M, Malats N, Piñol J, et al. Relevance of misclassification of disease status in epidemiologic studies of pancreatic cancer. Response to Silverman et al. J Clin Epidemiol 1996;49:602-3.

57 Silverman D, Schiffman M, Devesa S. Diagnostic certainty in pancreatic cancer. J Clin Epidemiol 1996;49:601-3.

58 Garabrant H, Held J, Homa D. DDT and pancreatic cancer. Response to Malats et al. J Natl Cancer Inst 1993;85:328-9. 
Table 1 Adjusted Odds Ratio (OR) for Exocrine Pancreatic Cancer and for Ductal Adenocarcinoma subtype separately, according to occupations* in Spanish men and women (at least 1 year worked in the occupation)

\begin{tabular}{|c|c|c|c|c|c|c|c|}
\hline \multirow[b]{2}{*}{ Sex } & \multirow[b]{2}{*}{$\begin{array}{l}\text { CNO94 } \\
\text { Code }^{\text {a b }} \\
\end{array}$} & \multirow[b]{2}{*}{$\begin{array}{l}\text { CNO94 } \\
\text { Job Titles } \\
\end{array}$} & \multirow{2}{*}{$\begin{array}{l}\text { Controls } \\
\mathrm{N}^{\mathrm{c}}\end{array}$} & \multicolumn{2}{|c|}{ All Pancreatic Cancer } & \multicolumn{2}{|c|}{ Ductal Adenocarcinoma } \\
\hline & & & & $\mathbf{N}^{\mathrm{c}}$ & OR $(95 \% \mathrm{Cl}))^{d}$ & $\mathbf{N}^{\mathrm{c}}$ & OR $(95 \% \mathrm{Cl})^{d}$ \\
\hline Both sexes & 50 & Housekeeping and restaurant services workers & $15 / 455$ & $6 / 161$ & $1.15(0.42-3.11)$ & $3 / 76$ & $1.23(0.33-4.62)$ \\
\hline Both sexes & 502 & Waiters, waitresses and bartenders & $7 / 455$ & $5 / 162$ & $2.38(0.70-8.00)$ & $3 / 76$ & $2.90(0.67-12.39)$ \\
\hline Men & 60 & Skilled workers in agricultural activities & $70 / 285$ & $27 / 96$ & $1.13(0.63-2.01)$ & $8 / 47$ & $0.85(0.35-2.06)$ \\
\hline Men & 601 & Self-employed skilled workers in agricultural activities & $66 / 285$ & $24 / 96$ & $1.04(0.58-188)$ & $7 / 47$ & $0.76(0.30-1.92)$ \\
\hline Men & 602 & Employed skilled workers in agricultural activities & $4 / 285$ & $4 / 96$ & $2.35(0.51-10.92)$ & $1 / 47$ & $2.28(0.22-23,83)$ \\
\hline Men & 6022 & Employed skilled workers in gardens, nurseries and vegetable or market gardens & $1 / 285$ & $3 / 96$ & $5.62(0.48-66.10)$ & $1 / 47$ & $8.98(0.38-210.26)$ \\
\hline Men & 72 & Building finishers and related trades workers & $13 / 285$ & $8 / 96$ & $2.66(0.99-7.17)$ & $5 / 47$ & $3.58(1.03-12.44)$ \\
\hline Men & 723 & Building and related electricians & $3 / 285$ & $3 / 96$ & $3.98(0.71-22.12)$ & $1 / 47$ & $1.78(0.12-24.75)$ \\
\hline Men & 724 & Painters and related workers & $4 / 285$ & $3 / 96$ & $2.77(0.56-13.68)$ & $2 / 47$ & $4.77(0.71-32.03)$ \\
\hline Men & 742 & Miners, shotfirers, stone cutters and carvers & $4 / 285$ & $3 / 96$ & $2.77(0.57-13.53)$ & $3 / 47$ & $8.14(1.55-42.68)$ \\
\hline Men & 7421 & Miners and quarry workers & $2 / 285$ & $1 / 96$ & $1.98(0.16-23.39)$ & $1 / 47$ & $6.32(0.49-81.22)$ \\
\hline Men & 7422 & shotfirers & $0 / 285$ & $2 / 96$ & Ind & $2 / 47$ & Ind \\
\hline Men & 76 & Machinery and Electrical and electronic equipment mechanics and fitters & $15 / 285$ & $11 / 96$ & $2.84(1.18-6.83)$ & $7 / 47$ & $3.61(1.24-10.47)$ \\
\hline Men & 761 & Machinery mechanics and fitters & $15 / 285$ & $8 / 96$ & $1.75(0.68-4.5)$ & $4 / 47$ & $1.68(0.48-5.86)$ \\
\hline Men & 7611 & Motor vehicle mechanics and fitters & $5 / 285$ & $2 / 96$ & $0.87(0.15-5.07)$ & $1 / 47$ & $1.08(0.11-10.52)$ \\
\hline Men & 7613 & Agricultural- or industrial-machinery mechanics and fitters & $10 / 285$ & $6 / 96$ & $2.42(0.79-7.35)$ & $3 / 47$ & $2.17(0.49-9.65)$ \\
\hline Men & 793 & Textile, garment and related trades workers & $7 / 285$ & $4 / 96$ & $1.57(0.42-5.91)$ & $1 / 47$ & $0.79(0.08-7.80)$ \\
\hline Men & 7931 & Fibre preparers & $3 / 285$ & $3 / 96$ & $3.42(0.62-18.71)$ & $1 / 47$ & $1.77(0.12-24.63)$ \\
\hline Men & 81 & Stationary plant and related operators & $17 / 285$ & $6 / 96$ & $1.22(0.43-3.41)$ & $1 / 47$ & $0.38(0.04-3.16)$ \\
\hline Men & 812 & Metal-processing plant operators & $8 / 285$ & $3 / 96$ & $1.90(0.46-7.90)$ & $1 / 47$ & $1.16(0.12-11.00)$ \\
\hline Men & 814 & Wood-processing- and papermaking-plant operators & $4 / 285$ & $2 / 96$ & $1.94(0.31-11.99)$ & $0 / 47$ & Ind \\
\hline Men & 8141 & Wood-processing-plant operators & $3 / 285$ & $2 / 96$ & $2.38(0.35-16.17)$ & $0 / 47$ & Ind \\
\hline Men & 831 & Metal- and mineral-products machine operators & $5 / 285$ & $4 / 96$ & $3.20(0.78-13.01)$ & $3 / 47$ & $4.22(0.84-21.04)$ \\
\hline Men & 8311 & Machine-tool operators & $4 / 285$ & $2 / 96$ & $1.86(0.31-11.05)$ & $1 / 47$ & 1. $57(0.15-16.54)$ \\
\hline Men & 86 & Motor vehicle drivers & $26 / 285$ & $12 / 96$ & $1.47(0.68-3.20)$ & $7 / 47$ & $1.56(0.58-4.14)$ \\
\hline Men & 863 & Heavy truck and lorry drivers & $10 / 285$ & $7 / 96$ & $2.45(0.84-7.09)$ & $5 / 47$ & $3.46(1.01-11.83)$ \\
\hline Women & 4 & Office Clerks & $3 / 170$ & $4 / 65$ & $4.39(0.65-29.26)$ & $3 / 29$ & $6.95(0.78-61.58)$ \\
\hline Women & 43 & Other Office Clerks & $1 / 170$ & $4 / 65$ & $14.20(1.16-173.67)$ & $3 / 29$ & $17.46(1.17-259.27)$ \\
\hline Women & 601 & Self-employed skilled workers in agricultural activities & $6 / 170$ & $3 / 65$ & $0.85(0.17-4.33)$ & $2 / 29$ & $1.38(0.21-9.27)$ \\
\hline Women & 836 & Textile-, fur- and leather-products machine operators & $10 / 170$ & $5 / 65$ & $1.32(0.40-4.36)$ & $4 / 29$ & $2.10(0.55-7.98)$ \\
\hline Women & 8366 & Shoemaking- and related machine operators & $4 / 170$ & $2 / 65$ & $1.24(0.16-9.45)$ & $2 / 29$ & $2.43(0.31-18.63)$ \\
\hline Women & 9110 & Domestic helpers and cleaners & $4 / 170$ & $1 / 65$ & $0.93(0.09-9.12)$ & $1 / 29$ & $1.85(0.19-17.70)$ \\
\hline Women & 912 & Helpers and cleaners in offices, hotels and other establishments & $6 / 170$ & $2 / 65$ & $0.76(0.13-4.34)$ & $2 / 29$ & $1.97(0.33-11.72)$ \\
\hline
\end{tabular}

a Selected occupations were those with at least 10 exposed subjects at one digit of CNO94 (see text in methods), or those reported as possible risk factors in published studies, provided that there were at least five exposed subjects;

${ }^{\mathrm{b}}$ The Spanish National Classification of Occupations 1994. One person can be included in more than one occupation.

${ }^{\circ} \mathrm{N}=$ Number of exposed controls and cases. Numerator denotes the number of controls \& cases who have worked in the mentioned occupation and the denominator denotes the total number of $\mathrm{N}=$ Number of exposed controls and cases. Numerator denotes the number of controls \& cases who have worked in the mentioned occupation and the denominator denotes the total number 0 controls \& cases according to sex respectively. d Odds ratio adjusted for sex, age, province, educational level, alcohol drinking and tobacco smoking. The reference category included all remaining Job-Tittles. Cl: confidence interval. Ind:
Indeterminate 
Table 2 Adjusted Odds Ratio (OR) for all exocrine pancreatic cancer and for ductal adenocarcinoma subtype, according to occupational exposures by FINJEM in both sexes

\begin{tabular}{|c|c|c|c|c|c|c|c|c|c|c|}
\hline \multirow{3}{*}{$\begin{array}{l}\text { Agents } \\
\text { CHEMICAL AGENTS }\end{array}$} & \multirow[b]{2}{*}{ Exposure level $^{a}$} & \multirow{2}{*}{$\frac{\text { Controls }}{\mathrm{N}^{\mathrm{b}} 455}$} & \multicolumn{4}{|c|}{ All Pancreatic Cancer } & \multicolumn{4}{|c|}{ Ductal Adenocarcinoma } \\
\hline & & & $\mathrm{N}^{\mathrm{b}} 161$ & OR $^{\mathrm{c}}$ & \multicolumn{2}{|c|}{$(95 \% \mathrm{Cl})$} & $N^{b} 76$ & $\mathbf{O R}^{\mathrm{c}}$ & \multicolumn{2}{|c|}{$(95 \% \mathrm{Cl})$} \\
\hline & & & & & & & & & & \\
\hline \multirow[t]{2}{*}{ Any pesticide ${ }^{d}$} & $\operatorname{Low}\left(\leq 0.018 \mathrm{mg} / \mathrm{m}^{3}\right)^{\mathrm{a}}$ & 72 & 25 & 0.99 & 0.57 & 1.72 & 9 & 0.87 & 0.39 & 1.97 \\
\hline & $\operatorname{High}\left(>0.018 \mathrm{mg} / \mathrm{m}^{3}\right)^{a}$ & 4 & 5 & 3.54 & 0.83 & 15.21 & 1 & 2.16 & 0.21 & 22.32 \\
\hline \multirow[t]{2}{*}{ Hydrocarbon solvents $\mathbb{I}$} & Low $(\leq 12.58 p p m)$ & 33 & 15 & 1.44 & 0.73 & 2.84 & 10 & 2.27 & 1.00 & 5.12 \\
\hline & High $(>12.58 p p m)$ & 10 & 2 & 0.77 & 0.16 & 3.72 & 1 & 0.62 & 0.07 & 5.41 \\
\hline \multirow[t]{2}{*}{ Hydrocarbon solvents_recode ${ }^{\mathrm{e}}$} & Low (lows in any of the subtypes below) & 17 & 8 & 1.42 & 0.56 & 3.62 & 4 & 1.56 & 0.46 & 5.31 \\
\hline & High (highs in any of the subtypes below) & 26 & 9 & 1.22 & 0.54 & 2.75 & 7 & 2.04 & 0.80 & 5.18 \\
\hline \multirow[t]{2}{*}{ Aliphatic hydrocarbon solvents } & Low $(\leq 9.10 p p m)$ & 23 & 12 & 1.65 & 0.76 & 3.59 & 7 & 2.19 & 0.83 & 5.79 \\
\hline & High $(>9.10 p p m)$ & 13 & 3 & 0.87 & 0.23 & 3.28 & 3 & 1.69 & 0.42 & 6.70 \\
\hline \multirow[t]{2}{*}{ Aromatic hydrocarbon solvents. } & Low $(\leq 17.65 p p m)$ & 18 & 7 & 1.27 & 0.49 & 3.29 & 6 & 2.70 & 0.95 & 7.64 \\
\hline & High $(>17.65 p p m)$ & 8 & 1 & 0.41 & 0.05 & 3.46 & 0 & Ind & & \\
\hline \multirow[t]{2}{*}{ Chlorinated hydrocarbon solvents } & Low $(\leq 0.83 p p m)$ & 5 & 1 & 0.86 & 0.09 & 7.84 & 1 & 1.17 & 0.11 & 12.26 \\
\hline & High (>0.83 ppm) & 8 & 5 & 1.99 & 0.62 & 6.42 & 4 & 4.11 & 1.11 & 15.23 \\
\hline \multirow[t]{2}{*}{ Other organic solvents } & Low $(\leq 11.49 p p m)$ & 10 & 4 & 1.06 & 0.31 & 3.65 & 3 & 1.94 & 0.46 & 8.17 \\
\hline & High (>11.49 ppm) & 11 & 2 & 0.60 & 0.12 & 2.90 & 2 & 1.13 & 0.22 & 5.79 \\
\hline \multirow[t]{2}{*}{ Formaldehyde } & Low $(\leq 0.014 p p m)$ & 79 & 27 & 0.90 & 0.53 & 1.55 & 9 & 0.75 & 0.34 & 1.70 \\
\hline & High (>0.014 ppm) & 24 & 6 & 0.79 & 0.30 & 2.08 & 3 & 0.88 & 0.24 & 3.23 \\
\hline \multirow[t]{2}{*}{ Polycyclic aromatic hydrocarbons (PAH) } & $\operatorname{Low}\left(\leq 0.15 \mu \mathrm{g} / \mathrm{m}^{3}\right)$ & 10 & 6 & 1.63 & 0.55 & 4.81 & 3 & 1.43 & 0.34 & 6.02 \\
\hline & High $\left(>0.15 \mu \mathrm{g} / \mathrm{m}^{3}\right)$ & 16 & 8 & 1.73 & 0.67 & 4.42 & 4 & 1.71 & 0.49 & 5.95 \\
\hline \multirow[t]{2}{*}{ Benzo(a)pyrene } & Low $\left(\leq 0.012 \mu \mathrm{g} / \mathrm{m}^{3}\right)$ & 11 & 6 & 1.53 & 0.53 & 4.44 & 3 & 1.39 & 0.33 & 5.78 \\
\hline & $\operatorname{High}\left(>0.012 \mu \mathrm{g} / \mathrm{m}^{3}\right)$ & 15 & 8 & 1.82 & 0.70 & 4.71 & 4 & 1.76 & 0.50 & 6.15 \\
\hline \multirow[t]{2}{*}{ Oil mist } & $\operatorname{Low}\left(\leq 1.79 \mathrm{mg} / \mathrm{m}^{3}\right)$ & 7 & 8 & 2.87 & 0.98 & 8.35 & 5 & 3.26 & 0.91 & 11.65 \\
\hline & $\operatorname{High}\left(>1.79 \mathrm{mg} / \mathrm{m}^{3}\right)$ & 10 & 3 & 0.89 & 0.23 & 3.50 & 1 & 0.39 & 0.04 & 3.49 \\
\hline \multirow[t]{2}{*}{ Diesel engine exhaust } & Low $\left(\leq 0.46 \mathrm{mg} / \mathrm{m}^{3}\right.$ nitrogen dioxide $)$ & 31 & 14 & 1.49 & 0.72 & 3.08 & 10 & 2.40 & 1.00 & 5.73 \\
\hline & High (>0.46 mg/m nitrogen dioxide) & 15 & 8 & 1.88 & 0.72 & 4.90 & 4 & 2.08 & 0.58 & 7.38 \\
\hline \multirow[t]{2}{*}{ Gasoline engine exhaust } & Low $\left(\leq 6.92 \mathrm{mg} / \mathrm{m}^{3}\right.$ carbon monoxide) & 26 & 11 & 1.38 & 0.62 & 3.07 & 7 & 1.66 & 0.63 & 4.43 \\
\hline & High (>6.92 mg/m carbon monoxide) & 15 & 8 & 1.85 & 0.71 & 4.80 & 4 & 1.88 & 0.53 & 6.62 \\
\hline Gasoline & -- & 15 & 8 & 1.78 & 0.69 & 4.60 & $4 /$ & 1.73 & 0.50 & 6.02 \\
\hline Bitumen fumes & - & 4 & 0 & Ind & & & 0 & Ind & & \\
\hline \multirow{2}{*}{ Environmental tobacco smoke } & Low $(\leq 0.119$ [based on a score $0-2]$ & 145 & 38 & 0.72 & 0.44 & 1.15 & 20 & 0.76 & 0.40 & 1.45 \\
\hline & High ( $>0.119$ [based on a score $0-2])$ & 38 & 21 & 1.60 & 0.84 & 3.06 & 10 & 1.39 & 0.58 & 3.31 \\
\hline \multirow[t]{2}{*}{ Asbestos } & Low $\left(\leq 0.26\right.$ fibers $\left./ \mathrm{cm}^{3}\right)$ & 75 & 31 & 1.30 & 0.77 & 2.18 & 18 & 2.09 & 1.05 & 4.13 \\
\hline & High $\left(>0.26\right.$ fibers $\left./ \mathrm{cm}^{3}\right)$ & 11 & 3 & 0.84 & 0.22 & 3.20 & 3 & 2.33 & 0.57 & 9.47 \\
\hline \multirow[t]{2}{*}{ Cadmium } & -- & 6 & 1 & 0.48 & 0.05 & 4.31 & 0 & Ind & & \\
\hline & -- & & & & & & & & & \\
\hline
\end{tabular}


(Table 2, Continued)

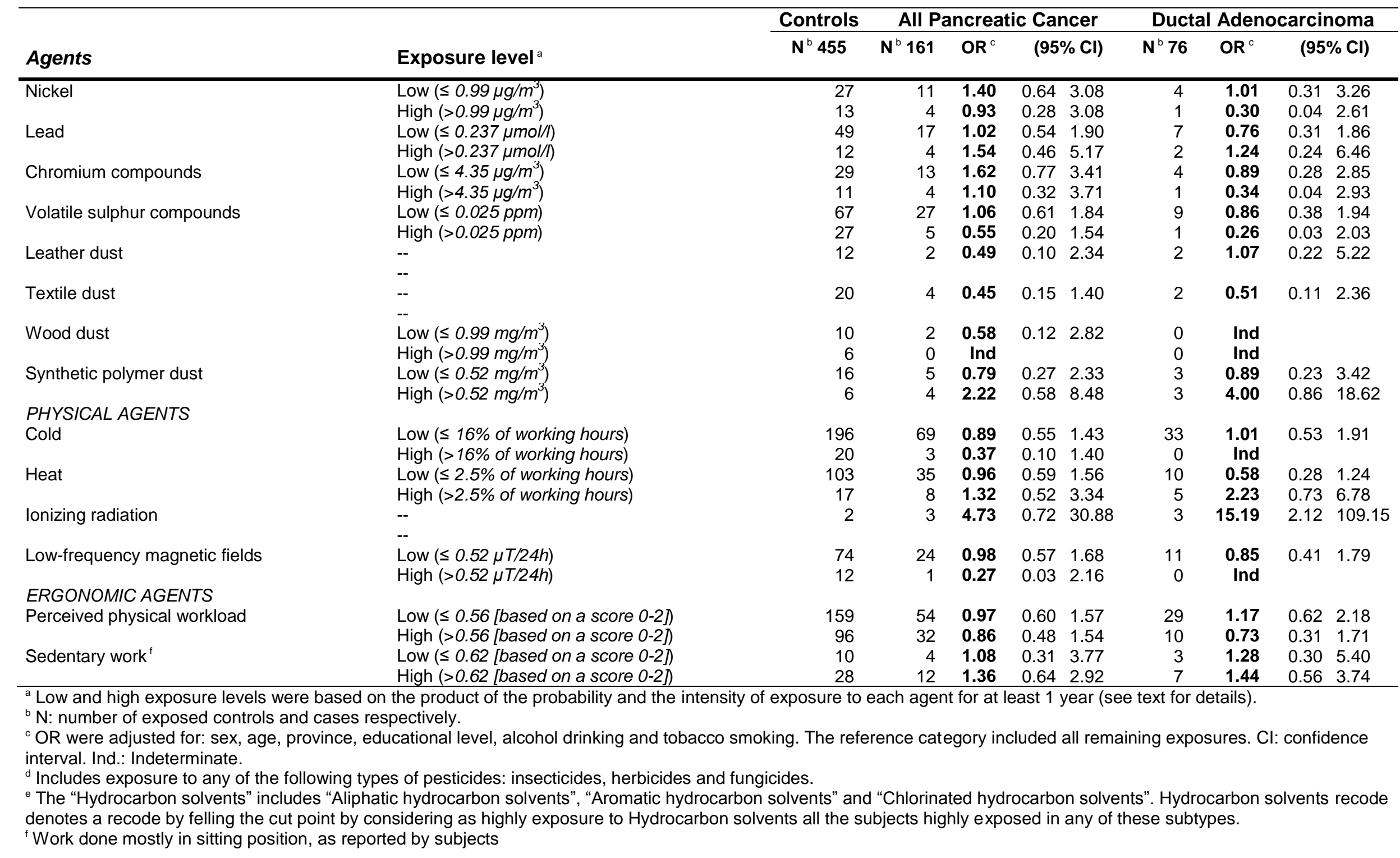

